\title{
Clothing Preferences of Elderly Women
}

\author{
Vivek Singh, Nisha Arya*, Neha Chauhan and Sarita Devi \\ Department of Textile and Apparel Designing, I. C. College of Home Science, \\ CCSHAU, Hisar, Haryana, India \\ *Corresponding author
}

\section{A B S T R A C T}

\begin{tabular}{|l|}
\hline Ke y w o r d s \\
Aesthetic, \\
Clothing, Elderly, \\
Fashionable, Fit \\
\hline Article Info \\
\hline $\begin{array}{l}\text { Accepted: } \\
\text { 15 February } 2019 \\
\text { Available Online: } \\
\text { 10 March 2019 }\end{array}$ \\
\hline
\end{tabular}

\section{Keywords}

Aesthetic,

Clothing, Elderly,

Fashionable, Fit

\section{Introduction}

Clothing is one domain that protect, to cover and to beautify his/ her body which is of great importance that is supposed to fulfill both functional and symbolic needs of the consumers (Nandini and Jeevananda, 2015). Clothing influences a person socially, psychologically and emotionally (Arya and Singh, 2017). Clothing that is neat and clean, fits well, and feels good can boost anyone's morale. Clothing should be appropriate for the person for whom it has been designed. Some of the important considerations which should be taken are climate of the region, season of the year for which the garment is made, the time or type of occasion when it is most likely to be worn, the type of role and age of person (Singh and Arya, 2017b).

Every change in a life- situation- birth, entering school, college, getting a job, marriage, parenthood and even death requires a change in wardrobe. Even in the course of daily life, situation after situation requires a change in dress to facilitate and symbolize the situational change. Old age is a period when women experiences lot of changes (Arya and Singh, 2016). Clothes mediate between the naked body and the social world, the self and society, presenting a means whereby social expectations in relation to age act upon and are made manifest in the body. They thus play a potentially important role in our 
understanding of the cultural processes of ageing (Arya et al., 2017).

Clothes are central to the ways older bodies are experienced, presented and understood within culture, so that dress forms a significant, though neglected, element in the constitution and experience of old age. Dress is, however, also an arena for the expression of identity.Clothing is significant because it mediates the relationship between the body and the social world, forming the vestimentary envelope that contains and makes manifest the body, offering a means whereby it is experienced, presented and given meaning in particular social contexts (Twigg, 2007).

Older people often are anxious about their appearance. They may be uncomfortable wearing the clothes they have, especially if those clothes are out of date, are in colors or designs that are no longer flattering, are mismatched, or simply no longer fit properly. Our clothing for elderly women needs for easy dressing, comfort and style while addressing the challenges of potential decreased mobility, need for maintenance of independence and the possible need for assisted dressing.

Older people have the right to make selections about their clothing. Clothing for elderly should be such that it makes them feel good about their appearance, and that will be easy to wear and care for. While selecting clothing for older people, the person's need for clothing that he or she enjoys; clothing that enhances appearance, increases independence, allows for function, and provides comfort must be considered. Clothing can help older people feel better about them and present a positive image to those around them. Sending positive appearance messages may increase older people's opportunities for social interaction. Good clothing choices for older people enhance appearance, increase independence, allow for daily functioning, and provide comfort, safety, and convenience.

Besides health factors, there are other factors that determine the clothing requirement of the elderly. These are the types of activities they engage in on a regular basis and culture. Clothing without doubt is central to the ways older bodies are experienced, presented, and understood within culture, so that 'clothing and age' forms a significant though neglected element in the constitution and experience of old age (Twigg, 2007).

This elaborate study revealed a lot about the relation between clothing, ageing and culture. It concluded that clothes are the primary means through which the body is presented, how dress operates in relation to age and is significant for understanding in what way cultural expectations act directly at a bodily level.

Furthermore, it revealed that clothing choices in old age reflect changes in the body and dress thus offers a field in which the complete interplay between physiological and cultural influences in the constitution of old age can be explored. Clothing has also traditionally embedded age ordering even though the phenomenon seems elusive. Clothing therefore is seen as an everyday bodily practice in which various influences including those of fashion, culture, age, identity, etc. come into play. Hence, study was conducted to determine the clothing needs of rural elderly women by gathering information on existing clothing practices, preferences and problems with existing dresses.

The main objectives includes to study the existing clothing practices of elderly women. And also to study the preferences of elderly women for various garments 


\section{Materials and Methods}

Interview schedule was prepared to collect information regarding clothing practices of elderly women and problems encountered with existing clothing practices. Their preferences for different types of garments, fabric and various constructional features for upper garments were also studied.

The experiment was conducted in four villagesof Sonipat district (Jagdishpur, Shahpur, Fazilpur and Raipur) of Haryana. The data was collected from twenty respondents from each village, comprising a total of eighty respondents.

Clothing practices of elderly women and their preferences for different types of garments were studied and responses were tabulated using frequency and percentages.

\section{Results and Discussion}

Clothing practices of elderly women and their preferences for different types of garments, fabric and various constructional features for upper garments were studied using self structured interview schedule. Information regarding clothing practices, problems encountered by rural elderly women with existing clothing practices, preferences regarding fabric and various constructional features of upper garments has been presented in Table 1 to 4 .

Data regarding existing clothing practices of rural elderly women has been presented in Table 1. It is clear from the data that half of the rural women (55\%), used to wear short straight kameez with salwar followed by kurti with salwar which was worn by $45 \%$ respondents.

Thus, majority of rural women used to wear straight kameez with salwar followed by kurtiwith salwar.
The data presented in Table 2 revealed that near about half of rural women (52.2 were not satisfied with length of opening in upper garments i.e. kameez \& kurti followed by the problem of improper length of armhole in upper garments faced by $32.5 \%$ rural elderly women. Thirty percent elderly women, also considered the use of stiffening material i.e. tetron in band, collar, cuffs and pauncha, uncomfortable. A few rural women i.e. 10\% also considered use of string in lower garment for tying as uncomfortable.

Thus, nearly half of rural women were not satisfied with length of front opening and thirty three percent with length of armhole.

The data related to various attributes of fabric preferred by rural elderly women has been presented in Table 3. The data revealed that majority of rural elderly women $(80 \%)$ preferred cotton blend fabric followed by cotton fabric by $20 \%$ respondents.

Light colors were preferred by majority of rural women $(80 \%)$. Twenty percent respondents preferred dark $\&$ dull colors.

As far as print of the fabric was concerned, it was found that hundred percent respondents preferred small \& dense floral prints followed by scattered prints, which were preferred by $22.5 \%$ rural elderly women. Plain fabric was also preferred by $15 \%$ respondents.

Thus, majority of rural elderly women preferred cotton blend fabric of light color with small dense floral prints.

The data regarding preference of rural elderly women for various constructional features of upper garments has been presented in Table 4 .

Data pertaining to silhouette of kameez showed that hundred percent respondents preferred straight silhouette of kameez 
followed by A-line silhouette of kurti with round hemline preferred by near about half of respondents $(45 \%)$.
It was found that near about half of the respondents $(55 \%)$ preferred 8 to 12 " long side slits in their kameez followed by 6 " long side slits in their kurti by $45 \%$ respondents.

Table.1 Existing clothing practices of rural elderly women $\mathrm{N}=80$

\begin{tabular}{|l|c|}
\hline Type of dresses & Respondents \\
\hline $\begin{array}{l}\text { Short straight kameez with } \\
\text { salwar }\end{array}$ & $44(55 \%)$ \\
\hline Kurti with salwar & $36(45 \%)$ \\
\hline Short kameez, with lehnga & - \\
\hline
\end{tabular}

Table.2 Problems encountered by rural elderly women with existing clothing practices $(\mathrm{N}=80)$

\begin{tabular}{|c|c|c|c|}
\hline S. & Problems & \multicolumn{2}{|c|}{ Frequency Percentage } \\
\hline 1. & Use of stiffening material is uncomfortable & 24 & 30 \\
\hline 2. & Improper length of armhole & 26 & 32.5 \\
\hline 3. & Improper length of opening & 42 & 52.5 \\
\hline 4. & Use of string & 08 & 10 \\
\hline
\end{tabular}

Table.3 Preferences of rural elderly women regarding fabric $(\mathrm{N}=80)$

\begin{tabular}{|l|l|c|}
\hline Features & Categories & Frequency (percentage) \\
\hline \multirow{5}{*}{ Fabric } & Cotton & $16(20 \%)$ \\
\hline & Cotton blend & $64(80 \%)$ \\
\hline & Synthetic & - \\
& Dark & $16(20 \%)$ \\
\cline { 2 - 3 } & Dull & $16(20 \%)$ \\
\hline \multirow{3}{*}{ Fabric print } & Bright & - \\
\cline { 2 - 3 } & Light & $64(80 \%)$ \\
\hline & Plain & $12(15 \%)$ \\
\hline & Floral & $80(100 \%)$ \\
\hline & Abstract & $80(100 \%)$ \\
\cline { 2 - 3 } & Small & - \\
\cline { 2 - 3 } & Bold & $80(100 \%)$ \\
\cline { 2 - 3 } & Dense & $18(22.5 \%)$ \\
\hline & Scattered & \\
\hline
\end{tabular}


Table.4 Preferences of respondents regarding various constructional features of upper garments $(\mathrm{N}=80)$

\begin{tabular}{|c|c|c|}
\hline Features & Categories & Frequency (percentage) \\
\hline \multirow{3}{*}{ Silhouette } & Straight & $80(100 \%)$ \\
\hline & A-line with round hemline & $36(45 \%)$ \\
\hline & Flared & - \\
\hline \multirow[t]{3}{*}{ Fitting } & Fitted all over & - \\
\hline & Loose all over & $80(100 \%)$ \\
\hline & Loose at bust to hip level & - \\
\hline \multirow{3}{*}{ Necklines } & Square & \\
\hline & Round & $44(55)$ \\
\hline & Neck with band /collar & $36(45)$ \\
\hline \multirow[t]{3}{*}{ Openings } & Front & $80(100 \%)$ \\
\hline & Back & - \\
\hline & Shoulder & - \\
\hline \multirow[t]{4}{*}{ Length of opening } & Up to bust line & - \\
\hline & Up to waistline & $80(100 \%)$ \\
\hline & Up to hip line & - \\
\hline & Full length & - \\
\hline \multirow[t]{2}{*}{ Sleeve type } & Simple & $80(100 \%)$ \\
\hline & Designed (with cuff) & $36(45 \%)$ \\
\hline \multirow[t]{3}{*}{ Sleeve length } & Half sleeves & - \\
\hline & $3 / 4$ sleeves & $80(100 \%)$ \\
\hline & full sleeve & $64(80 \%)$ \\
\hline \multirow[t]{3}{*}{ Side slits } & Up to $6 "$ & $36(45 \%)$ \\
\hline & $8-12 ”$ & $44(55 \%)$ \\
\hline & More than 12, & - \\
\hline
\end{tabular}

As far as fitting of upper garments was concerned, hundred percent respondents preferred all over loose upper garments i.e. lady's kameez and kurtis.

It is evident from the data presented in Table 4 that near about half of the respondents (55\%) preferred round neck followed by neck with band or collar by $45 \%$ respondents.

Hundred percent rural elderly women preferred front opening up to waist line in their upper garments.

The data regarding type of sleeve and length of sleeve indicated that hundred percent respondents preferred simple sleeve with $3 / 4$ length followed by full sleeve by $80 \%$ respondents.

It was concluded that all the respondents preferred straight all over loose kameez with up to waist line front opening and simple $3 / 4$ length sleeves.

In conclusion, a major common problem that many rural elderly women experience is the act of getting dressed and to undressed themselves. This might be the result of any physical disability, chronic condition, and/or other restrictions that comes with age. Therefore, as the result of major physiological 
changes at this specific stage, the clothing preferences of the elderly women have transformed from beautiful and designer to classic and functional. Elderly is the specific stage of life where functional clothing can be of countless help. Functional clothing makes life simpler for elderly women and also for their care takers.

\section{References}

Arya N, Singh V 2016. Preferences regarding constructional and designing features of kameez for urban lactating women. Indian Journal of Research, 5(10): 246-248.

Arya N, Singh V, Yadav N2017. Reliability assessment of functional clothing for lactating women. Asian Journal of Home Science, 12 (2):402-40.

Arya N, Singh V 2017. Existing clothing practices of urban lactating mothers. International Journal of Scientific Research, 6(4): 451-452.

Bhatia D, Malhotra U 2016. Thermophysiological Wear Comfort of Clothing: An Overview. Journal of Textile Science Engineering, 6(2): 1-8.

Gilleard C 2018. Suffering: The darker side of ageing. Journal of Aging Studies, 44: 28-33.

Lawrence R, Lawrence M, Robert M 2005. Breastfeeding - A guide for the medical profession sixth edition. Mosby. Philadelphia.

Nandini R, Jeevananda S 2015. A study on association between factors of fashion clothing and overall involvement. BIMS International Journal of Social
Science Research, 77-87.

Piacentini M, Mailer G 2009. Symbolic consumption in Teenagers clothing choices. Journal of Consumer Behaviour, 3(3): 251-262.

Raeve AD, Vasile S, Cools J 2018.Selected factors influencing wear comfort of clothing: case studies. Journal of Textile Engineering \& Fashion Technology, 4(1): 66-71.

Singh V, Arya N 2017a. Preferences regarding functional kameez for rural lactating women. International Research Journal of Human Resources and Social Sciences, 4(1):31-35.

Singh V, Arya N 2017b. Clothing practices of rural lactating women. International Journal of Applied Research, 3(4): 718-720.

Tuchtan V 2015. Helping the elderly with grooming and hygiene. Retrieved from http://www.sageagedcare.edu.au on November 28, 2018.

Twigg J 2007. "Clothing, age and the body: A critical review". Ageing. United Kingdom: Cambridge University Press.

Twigg J2009. Clothing, Identity and the Embodiment of Age. Aging and Identity: A Postmodern Dialogue, 119.

Wang X, Xu D 2010. Study on the Clothing for the Elderly. Proceedings of the 2010 International Conference on Information Technology and Scientific Management. Scientific Research. 5660 .

\section{How to cite this article:}

Vivek Singh, Nisha Arya, Neha Chauhan and Sarita Devi. 2019. Clothing Preferences of Elderly Women. Int.J.Curr.Microbiol.App.Sci. 8(03): 1813-1818. doi: https://doi.org/10.20546/ijcmas.2019.803.213 